Article

\title{
On Generalized Pata Type Contractions
}

\author{
Geno Kadwin Jacob ${ }^{1}$, M. S. Khan ${ }^{2}$, Choonkil Park ${ }^{3, *}$ and Sungsik Yun ${ }^{4, *}$ \\ 1 Department of Mathematics, Bharathidasan University, Tiruchirappalli-620 024, Tamil Nadu, India; \\ genomaths@gmail.com \\ 2 Department of Mathematics and Statistics, College of Science, Sultan Qaboos University, P.O. Box 36, \\ Muscat 123, Sultanate of Oman; mohammad@squ.edu.om \\ 3 Research Institute for Natural Sciences, Hanyang University, Seoul 04763, Korea \\ 4 Department of Financial Mathematics, Hanshin University, Gyeonggi-do 18101, Korea \\ * Correspondence: baak@hanyang.ac.kr (C.P.); ssyun@hs.ac.kr (S.Y.)
}

Received: 4 January 2018; Accepted: 30 January 2018; Published: 13 February 2018

\begin{abstract}
In this paper, the existence of fixed point for Pata type Zamfirescu mapping in a complete metric space is proved. Our result give existence of fixed point for a wider class of functions and also prove the existence of best proximity point to the result on "A fixed point theorem in metric spaces", given by vittorino Pata.
\end{abstract}

Keywords: Zamfirescu mapping; Pata mapping; fixed point; proximity point

MSC: primary 47H10; $54 \mathrm{H} 25$

\section{Introduction}

In 1922, Banach proved the existence of fixed point on a complete metric space $(X, d)$. The mapping $f$ has been considered to be a contraction and $f$ takes points of $X$ to itself. Later, several interpretations for the existence of fixed point with weaker conditions to contraction mappings were given. Later, Kannan type and Chatterjea type mappings were introduced. These were significant type of mappings since they provided the existence of fixed point for non-continuous mappings for the first time in literature. In 1972, Zamfirescu [1] introduced and gave the existence of fixed point for a generalized contraction mapping. This class of functions generalized the results of [2-4]. All of these mappings were compared by [5].

Throughout the paper, $\Theta$ denotes the class of all increasing functions $\Psi:[0,1] \rightarrow[0, \infty)$ such that $\Psi$ is continuous at 0 with $\Psi(0)=0$.

Definition 1. Let $(X, d)$ be a metric space. A mapping $f: X \rightarrow X$ is said to be a Zamfirescu mapping if, for all $x, y \in X$ and $a, b, c \in[0,1)$, it satisfies the condition

$$
d(f(x), f(y)) \leq \max \left\{a d(x, y), \frac{b}{2}[d(x, f(x))+d(y, f(y))], \frac{c}{2}[d(x, f(y))+d(y, f(x))]\right\} .
$$

In a recent paper, Pata [6] obtained the following refinement of the classical Banach Contraction Principle. Let $\Lambda \geq 0, \alpha \geq 1, \beta \in[0, \alpha]$ be any constants. For each $\epsilon \in[0,1]$,

$$
d(f(x), f(y)) \leq(1-\epsilon) d(x, y)+\Lambda \epsilon^{\alpha} \Psi(\epsilon)[1+\|x\|+\|y\|]^{\beta},
$$

where $\|x\|=d\left(x, x_{0}\right)$ for arbitrary $x_{0} \in X$ and $\Psi \in \Theta$.

In this paper, we define Pata type Zamfirescu mappings and prove the existence of fixed point in metric spaces, which generalizes the result of $[1,6]$. We also prove a best proximity point result that generalizes the result of [6]. 
The following lemma is used to prove our results.

Lemma 1. Suppose $(X, d)$ is a metric space. Let $\left\{x_{n}\right\}$ be a sequence in $X$ such that $d\left(x_{n}, x_{n+1}\right) \rightarrow 0$ as $n \rightarrow \infty$. If $\left\{x_{n}\right\}$ is not a Cauchy sequence, then there exist $a \delta>0$ and sequences of positive integers $\left\{m_{k}\right\}$ and $\left\{n_{k}\right\}$ with $m_{k}>n_{k}>k$ such that $d\left(x_{m_{k}}, x_{n_{k}}\right) \geq \delta, d\left(x_{m_{k}-1}, x_{n_{k}}\right)<\delta$ and

1. $\lim _{k \rightarrow \infty} d\left(x_{m_{k}-1}, x_{n_{k}+1}\right)=\delta$;

2. $\lim _{k \rightarrow \infty} d\left(x_{m_{k}}, x_{n_{k}}\right)=\delta$;

3. $\lim _{k \rightarrow \infty} d\left(x_{m_{k}-1}, x_{n_{k}}\right)=\delta$.

Using the above lemma, we get

$$
\begin{gathered}
\lim _{k \rightarrow \infty} d\left(x_{m_{k}+1}, x_{n_{k}+1}\right)=\delta, \\
\lim _{k \rightarrow \infty} d\left(x_{m_{k}}, x_{n_{k}-1}\right)=\delta .
\end{gathered}
$$

\section{Existence of Fixed Point for Pata Type Zamfirescu Mappings}

In this section, we prove the existence of unique fixed point for Pata type Zamfirescu mappings. Let $(X, d)$ be a metric space. In the sequel, we write $\|x\|=d\left(x, x_{0}\right)$, where $x_{0}$ is an arbitrary element in $X$.

Definition 2. Let $(X, d)$ be a complete metric space. A mapping $f: X \rightarrow X$ is said to be a Pata type Zamfirescu mapping if for all $x, y \in X, \Psi \in \Theta$ and for every $\epsilon \in[0,1], f$ satisfies the inequality

$$
d(f(x), f(y)) \leq(1-\epsilon) M(x, y)+\Lambda \epsilon^{\alpha} \Psi(\epsilon)[1+\|x\|+\|y\|+\|f(x)\|+\|f(y)\|]^{\beta},
$$

where $M(x, y)=\max \left\{d(x, y), \frac{d(x, f(x))+d(y, f(y))}{2}, \frac{d(x, f(y))+d(y, f(x))}{2}\right\}$ and $\Lambda \geq 0, \alpha \geq 1, \beta \in[0, \alpha]$ are constants.

Now, we show that all Zamfirescu mappings fall under a particular case of Pata type Zamfirescu mappings. Let $d=\max \{a, b, c\}$ in Definition 1 and consider the Bernoulli's inequality $(1+r t) \leq(1+t)^{r}$, $r \geq 1$ and $t \in[-1, \infty)$. Then,

$$
\begin{aligned}
d(f(x), f(y)) \leq & d \max \left\{d(x, y), \frac{d(x, f(x))+d(y, f(y))}{2}, \frac{d(x, f(y))+d(y, f(x))}{2}\right\} \\
\leq & (1-\epsilon) \max \left\{d(x, y), \frac{d(x, f(x))+d(y, f(y))}{2}, \frac{d(x, f(y))+d(y, f(x))}{2}\right\} \\
& +(d+\epsilon-1)\left[1+\max \left\{\|x\|+\|y\|, \frac{\|x\|+\|y\|+\|f(x)\|+\|f(y)\|}{2}\right\}\right] \\
\leq & (1-\epsilon) \max \left\{d(x, y), \frac{d(x, f(x))+d(y, f(y))}{2}, \frac{d(x, f(y))+d(y, f(x))}{2}\right\} \\
& +d\left(1+\frac{\epsilon-1}{d}\right)[1+\|x\|+\|y\|+\|f(x)\|+\|f(y)\|] \\
\leq & (1-\epsilon) \max \left\{d(x, y), \frac{d(x, f(x))+d(y, f(y))}{2}, \frac{d(x, f(y))+d(y, f(x))}{2}\right\} \\
& +d \epsilon^{\frac{1}{d}}[1+\|x\|+\|y\|+\|f(x)\|+\|f(y)\|] \\
\leq & (1-\epsilon) \max \left\{d(x, y), \frac{d(x, f(x))+d(y, f(y))}{2}, \frac{d(x, f(y))+d(y, f(x))}{2}\right\} \\
& +d \epsilon \epsilon^{\frac{1-d}{d}}[1+\|x\|+\|y\|+\|f(x)\|+\|f(y)\|] .
\end{aligned}
$$

Comparing this with Pata type Zamfirescu mappings, we have that Zamfirescu mapping is actually a special case of Pata type Zamfirescu mappings with $\Lambda=d, \Psi(\epsilon)=\epsilon^{\frac{1-d}{d}}$ and $\beta=1$. It is also clear that mappings given by [6-8] were also Pata type Zamfirescu mappings. 
Now, we prove the main result of this paper.

Theorem 1. Let $(X, d)$ be a complete metric space and let $f: X \rightarrow X$ be a Pata type Zamfirescu mapping. Then, $f$ has a unique fixed point in $X$.

Proof. Let $x_{0}$ be an arbitrary element in X. Define $x_{n+1}=f\left(x_{n}\right)$ and $c_{n}=d\left(x_{n}, x_{0}\right)$. To prove that $d\left(x_{n+1}, x_{n}\right)$ is a nonincreasing sequence, take $\epsilon=0$. Therefore,

$$
\begin{aligned}
d\left(x_{n+1}, x_{n}\right) \leq & \max \left\{d\left(x_{n}, x_{n-1}\right), \frac{d\left(x_{n}, f\left(x_{n}\right)\right)+d\left(x_{n-1}, f\left(x_{n-1}\right)\right)}{2}\right. \\
& \left.\frac{d\left(x_{n}, f\left(x_{n-1}\right)\right)+d\left(x_{n-1}, f\left(x_{n}\right)\right)}{2}\right\} \\
\leq & \max \left\{d\left(x_{n}, x_{n-1}\right), \frac{d\left(x_{n}, x_{n+1}\right)+d\left(x_{n-1}, x_{n}\right)}{2}, \frac{d\left(x_{n-1}, x_{n+1}\right)}{2}\right\} \\
\leq & \max \left\{d\left(x_{n}, x_{n-1}\right), \frac{d\left(x_{n}, x_{n+1}\right)+d\left(x_{n-1}, x_{n}\right)}{2}, \frac{d\left(x_{n}, x_{n-1}\right)+d\left(x_{n+1}, x_{n}\right)}{2}\right\} \\
\leq & \max \left\{d\left(x_{n}, x_{n-1}\right), \frac{d\left(x_{n}, x_{n+1}\right)+d\left(x_{n-1}, x_{n}\right)}{2}\right\} .
\end{aligned}
$$

Therefore, $d\left(x_{n+1}, x_{n}\right) \leq d\left(x_{n}, x_{n-1}\right) \leq \cdots \leq d\left(x_{1}, x_{0}\right)=c_{1}$.

Claim (1): $\left\{c_{n}\right\}$ is bounded.

$$
\begin{aligned}
c_{n}= & d\left(x_{n}, x_{0}\right) \\
\leq & d\left(x_{n}, x_{n+1}\right)+d\left(x_{n+1}, x_{1}\right)+d\left(x_{1}, x_{0}\right) \\
\leq & (1-\epsilon) \max \left\{d\left(x_{n}, x_{0}\right), \frac{d\left(x_{n}, x_{n+1}\right)+d\left(x_{0}, x_{1}\right)}{2}, \frac{d\left(x_{n}, x_{1}\right)+d\left(x_{0}, x_{n+1}\right)}{2}\right\} \\
& +2 c_{1}+\Lambda \epsilon^{\alpha} \Psi(\epsilon)\left[1+\left\|x_{n}\right\|+0+\left\|x_{n+1}\right\|+\left\|x_{1}\right\|\right]^{\beta} \\
\leq & (1-\epsilon) \max \left\{d\left(x_{n}, x_{0}\right), \frac{d\left(x_{n}, x_{n+1}\right)+d\left(x_{0}, x_{1}\right)}{2}, \frac{d\left(x_{n}, x_{1}\right)+d\left(x_{0}, x_{n+1}\right)}{2}\right\} \\
& +2 c_{1}+\Lambda \epsilon^{\alpha} \Psi(\epsilon)\left[1+\left\|x_{n}\right\|+d\left(x_{n+1}, x_{n}\right)+d\left(x_{n}, x_{0}\right)+\left\|x_{1}\right\|\right]^{\beta} \\
\leq & (1-\epsilon) \max \left\{d\left(x_{n}, x_{0}\right), \frac{d\left(x_{n}, x_{n+1}\right)+d\left(x_{0}, x_{1}\right)}{2}, \frac{d\left(x_{n}, x_{1}\right)+d\left(x_{0}, x_{n+1}\right)}{2}\right\} \\
& +2 c_{1}+\Lambda \epsilon^{\alpha} \Psi(\epsilon)\left[1+\left\|x_{n}\right\|+\left\|x_{1}\right\|+\left\|x_{n}\right\|+\left\|x_{1}\right\|\right]^{\beta} \\
\leq & (1-\epsilon) \max \left\{c_{n}, c_{1}, \frac{d\left(x_{n}, x_{0}\right)+d\left(x_{1}, x_{0}\right)+d\left(x_{n+1}, x_{n}\right)+d\left(x_{n}, x_{0}\right)}{2}\right\} \\
& +2 c_{1}+\Lambda \epsilon^{\alpha} \Psi(\epsilon)\left[1+\left\|x_{n}\right\|+\left\|x_{n}\right\|+\left\|x_{1}\right\|+\left\|x_{1}\right\|\right]^{\beta} \\
\leq & (1-\epsilon) \max \left\{c_{n}, c_{1}, c_{n}+c_{1}\right\}+2 c_{1}+\Lambda \epsilon \Psi(\epsilon)\left[1+2 c_{n}+2 c_{1}\right]^{\beta} \\
\leq & (1-\epsilon)\left[c_{n}+c_{1}\right]+2 c_{1}+\Lambda \epsilon^{\alpha} \Psi(\epsilon)\left[1+2 c_{n}+2 c_{1}\right]^{\alpha} .
\end{aligned}
$$

By the same reasoning as in [8], it follows that the sequence $\left\{c_{n}\right\}$ is bounded.

Let $\lim _{n \rightarrow \infty} d\left(x_{n}, x_{n-1}\right)=d$. Since $d\left(x_{n}, x_{n-1}\right)$ is nonincreasing, 


$$
\begin{aligned}
d\left(x_{n+1}, x_{n}\right)= & d\left(f\left(x_{n}\right), f\left(x_{n-1}\right)\right) \\
\leq & (1-\epsilon) \max \left\{d\left(x_{n}, x_{n-1}\right), \frac{d\left(x_{n}, x_{n+1}\right)+d\left(x_{n-1}, x_{n}\right)}{2},\right. \\
& \left.\frac{d\left(x_{n}, x_{n}\right)+d\left(x_{n-1}, x_{n+1}\right)}{2}\right\} \\
& +\Lambda \epsilon^{\alpha} \Psi(\epsilon)\left[1+\left\|x_{n}\right\|+\left\|x_{n-1}\right\|+\left\|x_{n+1}\right\|+\left\|x_{n}\right\|\right]^{\beta} \\
\leq & (1-\epsilon) \max \left\{d\left(x_{n}, x_{n-1}\right), \frac{d\left(x_{n}, x_{n+1}\right)+d\left(x_{n-1}, x_{n}\right)}{2}\right\}+K \epsilon \Psi(\epsilon) .
\end{aligned}
$$

Now, as $n \rightarrow \infty$, we get $d \leq K \Psi(\epsilon)$ and hence $d=0$.

Claim (2): The sequence $\left\{x_{n}\right\}$ is Cauchy. Suppose that $\left\{x_{n}\right\}$ is not a Cauchy sequence. Then, by Lemma 1, there exist subsequences $\left\{x_{n_{k}}\right\}$ and $\left\{x_{m_{k}}\right\}$ of $\left\{x_{n}\right\}$ with $n_{k}>m_{k}>k$ such that

$$
\begin{aligned}
\delta \leq d\left(x_{m_{k}}, x_{n_{k}}\right)= & d\left(f\left(x_{m_{k}-1}\right), f\left(x_{n_{k}-1}\right)\right) \\
\leq & (1-\epsilon) \max \left\{d\left(x_{m_{k}-1}, x_{n_{k}-1}\right), \frac{d\left(x_{m_{k}-1}, x_{m_{k}}\right)+d\left(x_{n_{k}-1}, x_{n_{k}}\right)}{2},\right. \\
& \left.\frac{d\left(x_{n_{k}-1}, x_{m_{k}}\right)+d\left(x_{m_{k}-1}, x_{n_{k}}\right)}{2}\right\}+K \epsilon \Psi(\epsilon) \\
\leq & (1-\epsilon) \max \left\{d\left(x_{m_{k}-1}, x_{n_{k}}\right)+d\left(x_{n_{k}}, x_{n_{k}-1}\right), \frac{d\left(x_{m_{k}-1}, x_{m_{k}}\right)+d\left(x_{n_{k}-1}, x_{n_{k}}\right)}{2},\right. \\
& \left.\frac{d\left(x_{n_{k}-1}, x_{m_{k}}\right)+d\left(x_{m_{k}-1}, x_{n_{k}}\right)}{2}\right\}+K \epsilon \Psi(\epsilon) .
\end{aligned}
$$

Now, as $k \rightarrow \infty$, we get $\delta \leq K \Psi(\epsilon)$, which is a contradiction. Therefore, $\left\{x_{n}\right\}$ is Cauchy. Since $X$ is complete, there exists $x \in X$ such that $x_{n} \rightarrow x$. Now, for all $n \in \mathbf{N}$ and for $\epsilon=0$, we obtain

$$
\begin{aligned}
d(f(x), x) \leq & d\left(f(x), x_{n+1}\right)+d\left(x_{n+1}, x\right) \\
\leq & \max \left\{d\left(x, x_{n}\right), \frac{d(x, f(x))+d\left(x_{n}, x_{n+1}\right)}{2},\right. \\
& \left.\frac{d\left(x, x_{n+1}\right)+d\left(x_{n}, f(x)\right)}{2}\right\}+d\left(x_{n+1}, x\right) .
\end{aligned}
$$

As $n \rightarrow \infty$, the above inequality concludes that $d(f(x), x) \leq \frac{1}{2} d(f(x), x)$. Hence, $x$ is a fixed point of $f$. For the uniqueness of fixed point, suppose that $x$ and $y$ are fixed points of $F$. Then,

$$
\begin{gathered}
d(f(x), f(y)) \leq(1-\epsilon) \max \left\{d(x, y), \frac{d(x, f(x))+d(y, f(y))}{2},\right. \\
\left.\frac{d(x, f(y))+d(y, f(x))}{2}\right\}+K \epsilon \Psi(\epsilon) .
\end{gathered}
$$

Therefore, we get $d(x, y) \leq K \Psi(\epsilon)$ and hence $x=y$. Therefore, $f$ has a unique fixed point in $X$.

Corollary 1. Let $(X, d)$ be a complete metric space and $f_{1}: X \rightarrow X$ be a Zamfirescu mapping satisfying, for all $x, y \in X$ and $a, b, c \in[0,1)$, the inequality

$$
d\left(f_{1}(x), f_{1}(y)\right) \leq \max \left\{a d(x, y), \frac{b}{2}\left[d\left(x, f_{1}(x)\right)+d\left(y, f_{1}(y)\right)\right], \frac{c}{2}\left[d\left(x, f_{1}(y)\right)+d\left(y, f_{1}(x)\right)\right]\right\} .
$$

Then, $f_{1}$ has a unique fixed point in $X$. 
Proof. Using inequality (2), we obtain that

$$
\begin{aligned}
d\left(f_{1}(x), f_{1}(y)\right) \leq & (1-\epsilon) \max \left\{d(x, y), \frac{d\left(x, f_{1}(x)\right)+d\left(y, f_{1}(y)\right)}{2}, \frac{d\left(x, f_{1}(y)\right)+d\left(y, f_{1}(x)\right)}{2}\right\} \\
& +d \epsilon \epsilon^{\frac{1-d}{d}}\left[1+\|x\|+\|y\|+\left\|f_{1}(x)\right\|+\left\|f_{1}(y)\right\|\right] .
\end{aligned}
$$

Therefore, by Theorem $1, f_{1}$ has a unique fixed point in $X$.

Corollary 2. Let $(X, d)$ be a complete metric space and $f: X \rightarrow X$ be a mapping which satisfies (1). Then, $f$ has a unique fixed point in $X$.

\section{Existence of Best Proximity Point for Pata Type Proximal Contraction}

In this section, we define Pata type proximal mappings and prove the existence of best proximity points. Our work generalizes the result of [6]. Let $A$ and $B$ be two closed subsets of a complete metric space $(X, d)$. We denote by $A_{0}$ the subset of $A$ defined by

$$
A_{0}=\{x \in A: d(x, y)=d(A, B) \text {, for some } y \in B\} .
$$

Similarly, we denote by $B_{0}$ the subset of $B$ defined by

$$
B_{0}=\{y \in B: d(x, y)=d(A, B) \text {, for some } x \in A\} .
$$

Throughout this section, we assume that $A_{0}$ and $B_{0}$ are closed subsets of $A$ and $B$.

Definition 3. A mapping $f: A \rightarrow B$ is said to be a Pata type proximal contraction if for all $x, y \in A, \Psi \in \Theta$ and for every $\epsilon \in[0,1], f$ satisfies the inequality

$$
d(u, v) \leq(1-\epsilon) d(x, y)+\Lambda \epsilon^{\alpha} \Psi(\epsilon)[1+\|x\|+\|y\|]^{\beta},
$$

where $d(f(x), u)=d(f(y), v)=d(A, B)$ and $\Lambda \geq 0, \alpha \geq 1, \beta \in[0, \alpha]$ are any constants.

Theorem 2. Let $A$ and $B$ be two closed subsets of a complete metric space $(X, d)$. Let $f: A \rightarrow B$ be a Pata type proximal contraction such that $f\left(A_{0}\right) \subset B_{0}$. Then, $f$ has a best proximity point in $A$.

Proof. Let $x_{0}$ be an element in $A_{0}$. Then, $f\left(x_{0}\right) \in B_{0}$ and so there exists an element $x_{1} \in A_{0}$ such that $d\left(f\left(x_{0}\right), x_{1}\right)=d(A, B)$. Similiarly, define $x_{n+1} \in A_{0}$ such that $d\left(x_{n+1}, f\left(x_{n}\right)\right)=d(A, B)$ and $c_{n}=d\left(x_{n}, x_{0}\right)$. Then, we get

$$
\left.d\left(x_{n}, x_{n+1}\right)\right) \leq(1-\epsilon) d\left(x_{n-1}, x_{n}\right)+\Lambda \epsilon^{\alpha} \Psi(\epsilon)\left[1+\left\|x_{n}\right\|+\left\|x_{n-1}\right\|\right]^{\beta}
$$

for all $\epsilon \in[0,1]$.

In particular, letting $\epsilon=0$ in the inequality (3), we obtain that $d\left(x_{n+1}, x_{n}\right)$ is a nonincreasing sequence.

Therefore, $d\left(x_{n+1}, x_{n}\right) \leq d\left(x_{n}, x_{n-1}\right) \leq \ldots \leq d\left(x_{1}, x_{0}\right)=c_{1}$. 
Next, we prove that $\left\{c_{n}\right\}$ is bounded:

$$
\begin{aligned}
c_{n} & =d\left(x_{n}, x_{0}\right) \\
& \leq d\left(x_{n}, x_{n+1}\right)+d\left(x_{n+1}, x_{1}\right)+d\left(x_{1}, x_{0}\right) \\
& \leq(1-\epsilon) d\left(x_{n}, x_{0}\right)+2 c_{1}+\Lambda \epsilon^{\alpha} \Psi(\epsilon)\left[1+\left\|x_{n}\right\|+\left\|x_{0}\right\|\right]^{\beta} \\
& \leq(1-\epsilon) c_{n}+2 c_{1}+\Lambda \epsilon \Psi(\epsilon)\left[1+c_{n}+c_{1}\right]^{\beta} .
\end{aligned}
$$

Now, as in [6], we see that $\left\{c_{n}\right\}$ is bounded.

Let $\lim _{n \rightarrow \infty} d\left(x_{n}, x_{n-1}\right)=d$. Since $d\left(x_{n}, x_{n-1}\right)$ is nonincreasing,

$$
\begin{aligned}
d\left(x_{n+1}, x_{n}\right) & \leq(1-\epsilon) d\left(x_{n}, x_{n-1}\right)+\Lambda \epsilon^{\alpha} \Psi(\epsilon)\left[1+\left\|x_{n}\right\|+\left\|x_{n-1}\right\|\right]^{\beta} \\
& \leq(1-\epsilon) d\left(x_{n}, x_{n-1}\right)+K \epsilon \Psi(\epsilon) .
\end{aligned}
$$

As $n \rightarrow \infty$, we get $d \leq K \Psi(\epsilon)$ and hence $d=0$. Now, we claim that $\left\{x_{n}\right\}$ is a Cauchy sequence. Suppose that $\left\{x_{n}\right\}$ is not a Cauchy sequence. Then, by Lemma 1, there exist subsequences $\left\{x_{n_{k}}\right\}$ and $\left\{x_{m_{k}}\right\}$ of $\left\{x_{n}\right\}$ with $n_{k}>m_{k}>k$ such that

$$
\begin{aligned}
\delta \leq d\left(x_{m_{k}}, x_{n_{k}}\right) & \leq(1-\epsilon) d\left(x_{m_{k}-1}, x_{n_{k}-1}\right)+K \epsilon \Psi(\epsilon) \\
& \leq(1-\epsilon)\left[d\left(x_{m_{k}-1}, x_{n_{k}}\right)+d\left(x_{n_{k}}, x_{n_{k}-1}\right)\right]+K \epsilon \Psi(\epsilon) .
\end{aligned}
$$

Now, as $k \rightarrow \infty$, we get $\delta \leq K \Psi(\epsilon)$, which is a contradiction. Therefore, $\left\{x_{n}\right\}$ is a Cauchy sequence. Since $X$ is complete, there exists $x \in X$ such that $\left\{x_{n}\right\} \rightarrow x$. Let $d(u, f(x))=d(A, B)$ and $\epsilon=0$. Then, for all $n \in \mathbf{N}$, we get

$$
\begin{aligned}
d(u, x) & \leq d\left(u, x_{n+1}\right)+d\left(x_{n+1}, x\right) \\
& \leq d\left(x, x_{n}\right)+d\left(x_{n+1}, x\right),
\end{aligned}
$$

which concludes that $d(u, x)=0$. Hence, $x$ is a proximity point of $f$.

Suppose that $x$ and $y$ are proximity points of $f$. Then,

$$
d(x, y) \leq(1-\epsilon) d(x, y)+K \epsilon \Psi(\epsilon) .
$$

Therefore, we get $d(x, y) \leq K \Psi(\epsilon)$ and hence $x=y$. Thus, $x$ is the only proximity point of $f$ in $A$.

Corollary 3. Let $(X, d)$ be a complete metric space and $f: X \rightarrow X$ be a mapping which satisfies condition (1). Then, $f$ has a unique fixed point in $X$.

Proof. The proof follows directly from the previous theorem, when $A=B$.

In complete metric space setting, the following example shows the existence of best proximity of Pata type proximal contraction.

Example 1. Consider $A=\{(0, a) \mid a \in[0,1]\}$ and $B=\{(1, b) \mid b \in[0,1]\}$ on $\mathbb{R}^{2}$ under 1 -norm with $d(A, B)=1$. For $x \in A$, define $f: A \rightarrow B$ as $f(0, x)=\left(1, \frac{x^{2}}{4}\right), \Lambda=\alpha=\beta=1$, and for $\delta \in\left(0, \frac{1}{2}\right)$

$$
\psi(x)=\left\{\begin{array}{l}
\frac{x}{2} \text { if } x \in[0, \delta), \\
1 \text { if } x \in[\delta, 1] .
\end{array}\right.
$$


It has to be shown that, for all $\epsilon \in[0,1]$, $f$ satisfies the inequality of Pata type proximal contraction (i.e.,)...

$$
\left\{\begin{array}{l}
\text { for } \epsilon=0 \quad \Longrightarrow d(u, v) \leq d(x, y) \\
\text { for } \epsilon \in(0,1] \Longrightarrow d(u, v) \leq(1-\epsilon) d(x, y)+\epsilon \Psi(\epsilon)[1+\|x\|+\|y\|] .
\end{array}\right.
$$

The next inequality shows that $f$ satisfies the first case if $\epsilon=0$. For $\epsilon=0$ and for all $(0, x),(0, y) \in A$,

$$
\begin{aligned}
d(u, v)=d\left(\left(0, \frac{x^{2}}{4}\right),\left(0, \frac{y^{2}}{4}\right)\right) & =|0|+\left|\frac{x^{2}}{4}-\frac{y^{2}}{4}\right| \\
& =\left|\left(\frac{x}{2}+\frac{y}{2}\right)\left(\frac{x}{2}-\frac{y}{2}\right)\right| \\
& \leq d(x, y) .
\end{aligned}
$$

The following inequalities shows that $f$ satisfies second case if $\epsilon \in(0,1]$.

For $\epsilon \in(0, \delta)$ and for all $(0, x),(0, y) \in A$,

$$
\begin{aligned}
d(u, v)=d\left(\left(0, \frac{x^{2}}{4}\right),\left(0, \frac{y^{2}}{4}\right)\right) & =|0|+\left|\frac{x^{2}}{4}-\frac{y^{2}}{4}\right| \\
& \leq \frac{1}{2}|x-y| \\
& =\frac{1}{2} d(x, y) \\
& =(1-\epsilon) d(x, y)+\left(\frac{1}{2}+\epsilon-1\right) d(x, y) \\
& =(1-\epsilon) d(x, y)+\frac{1}{2}\left(1+\frac{\epsilon-1}{\frac{1}{2}}\right)\left[d\left(x, x_{0}\right)+d\left(y, x_{0}\right)\right] \\
& \leq(1-\epsilon) d(x, y)+\frac{1}{2} \epsilon^{2}\left[d\left(x, x_{0}\right)+d\left(y, x_{0}\right)\right] \\
& =(1-\epsilon) d(x, y)+\epsilon \Psi(\epsilon)[1+\|x\|+\|y\|] .
\end{aligned}
$$

For $\epsilon \in[\delta, 1]$ and for all $(0, x),(0, y) \in A$,

$$
\begin{aligned}
d(u, v)=d\left(\left(0, \frac{x^{2}}{4}\right),\left(0, \frac{y^{2}}{4}\right)\right) & =|0|+\left|\frac{x^{2}}{4}-\frac{y^{2}}{4}\right| \\
& \leq d(x, y) \\
& =(1-\epsilon) d(x, y)+\epsilon d(x, y) \\
& \leq(1-\epsilon) d(x, y)+\epsilon\left[d\left(x, x_{0}\right)+d\left(y, x_{0}\right)\right] \\
& \leq(1-\epsilon) d(x, y)+\epsilon \Psi(\epsilon)[1+\|x\|+\|y\|]
\end{aligned}
$$

Therefore, $f$ is Pata type proximal contraction and hence there exists a best proximity point $(0,0)$ in $A$.

Author Contributions: Geno Kadwin Jacob , M. S. Khan, Choonkil Park and Sungsik Yun conceived and wrote the paper.

Conflicts of Interest: The authors declare no conflict of interest.

\section{References}

1. Zamfirescu, T. Fixed point theorems in metric spaces. Arch. Math. 1972, 23, 292-298.

2. Banach, S. Sur les operations dans les ensembles abstraits et leurs applications aux equations integrales. Fund. Math. 1922, 3, 133-181. 
3. Chatterjea, S.K. Fixed-point theorems. C. R. Acad. Bulg. Sci. 1972, 25, 727-730.

4. Kannan, V. Some results on fixed points. Bull. Calcutta Math. Soc. 1968, 60, 71-76.

5. Rhoades, B.E. A comparision of various definitions of contractive mappings. Trans. Am. Math. Soc. 1977, 226, 257-290.

6. Pata, V. A fixed point theorem in metric spaces. J. Fixed Point Theory Appl. 2011, 10, $299-305$.

7. Chakraborty, M.; Samanta, S.K. On a fixed point theorem for a cyclical Kannan-type mapping, pre-print (2012). Facta Univ. Ser. Math. Inform. 2013, 28, 179-188.

8. Kadelburg, Z.; Radenovic, S. Fixed point theorems under Pata-type conditions in metric spaces. J. Egypt. Math. Soc. 2016, 24, 77-82.

(C) 2018 by the authors. Licensee MDPI, Basel, Switzerland. This article is an open access article distributed under the terms and conditions of the Creative Commons Attribution (CC BY) license (http:/ / creativecommons.org/licenses/by/4.0/). 